\title{
Efficacy of pre-operative stereotactic radiosurgery followed by surgical resection and correlative radiobiological analysis for patients with 1-4 brain metastases: study protocol for a phase II trial
}

Wei X. Huff ${ }^{1}$, Namita Agrawal' ${ }^{2}$ Scott Shapiro', James Miller ${ }^{1}$, Charles Kulwin ${ }^{1}$, Mitesh Shah', Jesse J. Savage ${ }^{1}$, Troy Payner ${ }^{1}$, Alexander Vortmeyer ${ }^{3}$, Gordon Watson ${ }^{2}$ and Mahua Dey ${ }^{{ }^{*}}$

\begin{abstract}
Background: Stereotactic radiosurgery (SRS) has emerged as a common adjuvant modality used with surgery for resectable brain metastases (BMs). However, the optimal sequence of the multi-modality therapy has not been established. The goal of the study is to evaluate 6-month local control utilizing pre-operative SRS followed by surgical resection for patients with 1-4 brain metastases.

Methods: This prospective, single arm, phase II trial will recruit patients with up to 4 brain metastases and at least one resectable lesion. All lesions will be treated with SRS and symptomatic lesions will be resected within 1-4 days after SRS. Patients will be monitored for 6-month local control, in-brain progression free survival, distant in-brain failure, rate of leptomeningeal spread, radiation necrosis and overall survival. Additionally, we will also perform correlative radiobiological molecular studies to assess the effect of radiation dosing on the tumor tissue and clinical outcomes. We expect that pre-operative SRS to the gross tumor prior to surgical resection will improve local control and decrease leptomeningeal failure.

Discussion: Our study is the second prospective trial to investigate the efficacy of pre-operative SRS in the treatment of multiple BMs. In addition, the correlative molecular studies will be the first to investigate early response of BMs at a cellular and genetic level in response to radiation doses and potentially provide molecular prognostic markers for local control and overall survival.
\end{abstract}

Trial registration: Clinicaltrials.gov identifier: NCT03398694 (registration date: January 12, 2018).

Keywords: Stereotactic radiosurgery, Brain metastases, Metastases surgery, Immune profiling, Molecular profiling

\footnotetext{
* Correspondence: mdey@iu.edu

${ }^{1}$ Department of Neurosurgery, Indiana University School of Medicine, Indiana

University Purdue University Indianapolis, Neuroscience Research Building,

320 W 15th Street, NB 400A, Indiana, IN 46202, USA

Full list of author information is available at the end of the article
}

(c) The Author(s). 2018 Open Access This article is distributed under the terms of the Creative Commons Attribution 4.0 International License (http://creativecommons.org/licenses/by/4.0/), which permits unrestricted use, distribution, and reproduction in any medium, provided you give appropriate credit to the original author(s) and the source, provide a link to the Creative Commons license, and indicate if changes were made. The Creative Commons Public Domain Dedication waiver (http://creativecommons.org/publicdomain/zero/1.0/) applies to the data made available in this article, unless otherwise stated. 


\section{Issue Section}

Research - Human - Study protocols

\section{GENERAL INFORMATION}

Pre-operative stereotactic radiosurgery followed by resection for patients with brain metastases

\section{Study Dates}

January 12, 2018, currently recruiting

Investigators: Table 1

- Research Site: IU Health Methodist Hospital 1701 N Senate Ave. Indianapolis IN 46202 Phone \# 317 962-2000

\section{Background}

Incidence of brain metastases (BMs) is increasing with improved systemic therapies, many of which have a limited impact on intracranial disease. $[1,2]$ Historically a combination of surgical removal with subsequent whole brain radiation therapy (WBRT) was the gold standard for managing patients with a single, large BM and WBRT alone for patients with multiple metastases. [3, 4] Recent advances in the systemic treatment of various cancers have resulted in long-term survivors. [1, 2, 5] WBRT is associated with debilitating neurocognitive dysfunction, which results in significant impairment in the quality of life of long-term survivors. [6-9] As a result, current practice patterns shifted away from use of WBRT for oligo-metastasis, defined as limited number of BMs, reserving WBRT as salvage therapy or for disseminated BMs. $[9,10]$ Stereotactic radiosurgery (SRS) delivers high dose of radiation in a highly conformal way to relatively small target $(<3 \mathrm{~cm})$ with minimal radiation to the surrounding normal tissue. [11] Since its conception, SRS emerged as a leading modality to treat BMs in variety of clinical scenarios including a boost with WBRT, as definitive treatment alone for patients with limited number of BMs and as an adjuvant treatment modality in pre- or post-operative setting. [12-14] Many tumors, regardless of whether they are radiosensitive or resistant, single or multiple, can be adequately managed with SRS. [10, 11, 15]

Although there has been no consensus on combination therapy with surgery and SRS [16, 17], surgical resection continues to play an important role in patients with a limited number of BMs and relatively good performance status where: 1) pathological diagnosis is needed, 2) a large $\mathrm{BM}(>2 \mathrm{~cm})$ causing significant mass effect necessitating direct decompression, and/or 3) neurological signs and symptoms refractory to corticosteroid management. [18, 19] Therefore, for patients with 1-4 BMs, especially in the above mentioned scenarios, adjuvant radiosurgery for surgically resected lesions is a common practice to achieve high LC. $[9,10]$

Several clinical studies evaluating the role of post-operative SRS in management of BMs concluded that SRS is a safe and effective adjuvant treatment strategy for BMs (Table 2). A systematic review of 14 studies involving 629 patients treated with SRS after surgical

Table 1 Investigators Details

\begin{tabular}{|c|c|c|c|}
\hline Name & Title & Role & Address \\
\hline Gordon A. Watson MD, PhD & $\begin{array}{l}\text { Associate Professor of Clinical } \\
\text { Radiation Oncology }\end{array}$ & Principle Investigator (Clinical Trial) & $\begin{array}{l}535 \text { Barnhill Drive } \\
\text { RT } 041 \text { RAON } \\
\text { Indianapolis IN } 46202 \\
\text { Phone \# 317-962-3172 }\end{array}$ \\
\hline Mahua Dey MD & $\begin{array}{l}\text { Assistant Professor of } \\
\text { Neurological Surgery } \\
\text { Adjunct Assistant Professor of } \\
\text { Microbiology and Immunology }\end{array}$ & $\begin{array}{l}\text { Co-Investigator (Clinical Trial) } \\
\text { Principle Investigator (Correlative } \\
\text { Radiobiological Analysis) }\end{array}$ & $\begin{array}{l}\text { Dey Laboratory } \\
\text { Indiana University School } \\
\text { of Medicine } \\
\text { Neuroscience Research Building } \\
320 \text { W 15th Street NB 400A } \\
\text { Indianapolis IN 46202 } \\
\text { Phone \# 317-274-2601 }\end{array}$ \\
\hline Alexander O Vortmeyer MD, PhD & $\begin{array}{l}\text { Professor of Clinical Pathology } \\
\text { and Laboratory Medicine }\end{array}$ & $\begin{array}{l}\text { Co-Investigator (Clinical Trial and } \\
\text { Correlative Radiobiological Analysis) }\end{array}$ & $\begin{array}{l}\text { Pathology and Laboratory Med } \\
\text { IU Health Pathology Laboratory } \\
350 \text { W } 11 \text { th Street Room } 4034 \\
\text { Indianapolis IN } 46202 \\
\text { Phone \# 317-274-1618 }\end{array}$ \\
\hline Namita Agarwal MD & Resident Physician of Radiation Oncology & Co-Investigator (Clinical Trial) & $\begin{array}{l}535 \text { Barnhill Drive } \\
\text { RT } 041 \text { RAON } \\
\text { Indianapolis IN } 46202 \\
\text { Phone \# 317-962-3172 }\end{array}$ \\
\hline Sandra Althouse MS & Department of Radiation Oncology & Statistician & $\begin{array}{l}535 \text { Barnhill Drive } \\
\text { RT } 041 \text { RAON } \\
\text { Indianapolis IN } 46202 \\
\text { Phone \# 317-962-3172 }\end{array}$ \\
\hline
\end{tabular}




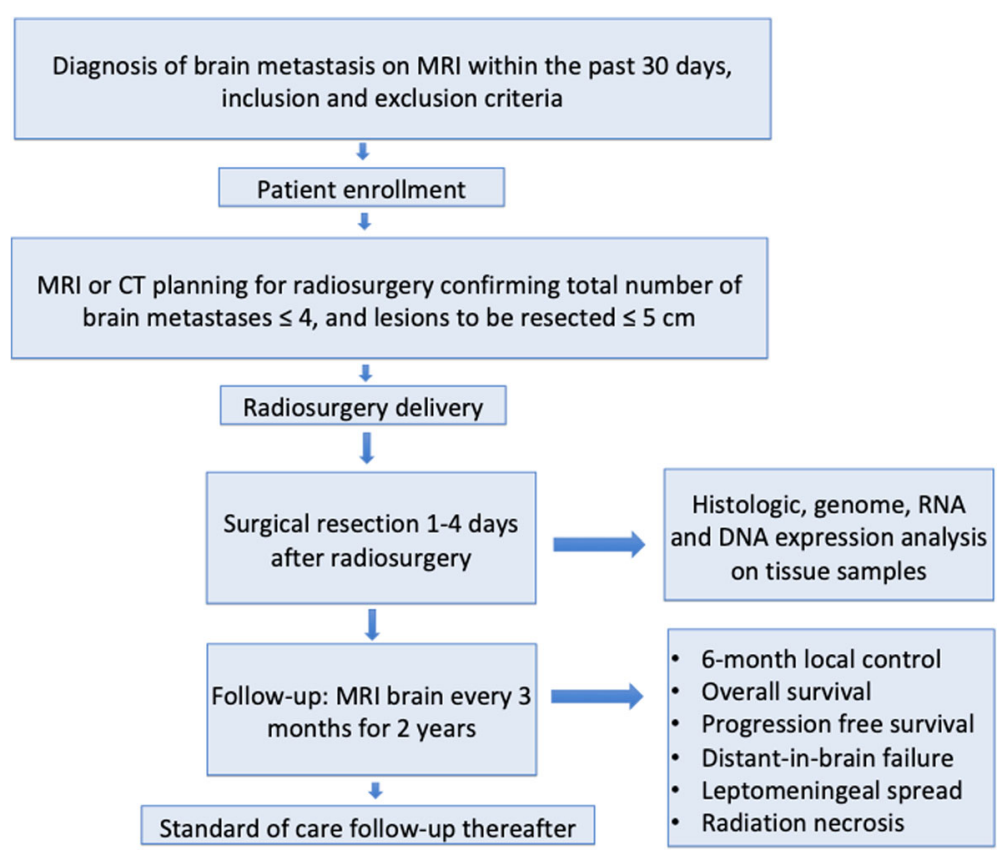

Fig. 1 Flow chart describing the clinical trial study design

resection showed pooled LC rate of $83 \%$, distant intracranial failure of $49 \%$ and need for salvage WBRT in $29 \%$ of cases. [20] In addition, time to salvage therapy from initial resection was found to be 8.4 months and $10-33 \%$ of patients suffered cavity-SRS induced complications such as radiation-induced edema in $43 \%$ and radiation necrosis (RN) in 23\%. [20] Two recently published phase III trials of post-operative SRS by Mahajan et al. and Brown et al. demonstrated local control efficacy and neurocognitive preservation compared with WBRT, respectively. $[9,21]$ Mahajan et al. prospectively randomized 132 patients in a single institution phase III study comparing observation and post-operative SRS and showed a significant improvement in local tumor recurrence-free rate at 12-month in post-operative SRS arm (72\%) compared to observation arm (43\%). [21] In the same journal issue, Brown et al. reported a multi -center prospective randomized phase III study to compare the post-operative SRS and WBRT in a total of 194 patients and observed similar overall survival but significantly improved neurocognition in post-operative SRS compared with WBRT. [9] Interestingly, their secondary endpoint analysis demonstrated a lower surgical bed and local control rate as compared to data previously reported. $[9,21]$ With a 6-month surgical bed control of $80.4 \%$ and an estimated $60.5 \%$ at 12 -month, the author discussed that lower LC rate after SRS could be due to falsely elevated frequency of recurrence by including

Table 2 Published studies of Post-op SRS after Metastases Resection

\begin{tabular}{|c|c|c|c|c|c|}
\hline Study & Treatment Modalities & Number of Patients & Median survival (months) & LR (\%) & $\mathrm{DBF}(\%)$ \\
\hline Bahl, 2006 [36] & $\mathrm{Op}+\mathrm{SRS} / \mathrm{fSRT}$ & 7 & 8.9 & 57.1 & 14.3 \\
\hline Kim, 2006 [37] & Op + GKRS & 79 & 16 & 5.1 & NA \\
\hline Soltys, 2008 [22] & $\mathrm{Op}+\mathrm{CK}$ & 72 & 15.1 & 21 & 49.2 \\
\hline Iwai, 2008 [38] & Op + GKRS & 21 & 20 & 23.8 & 47.6 \\
\hline Mathieu, 2008 [39] & Op + GKRS & 40 & 13 & 27 & 54.1 \\
\hline Limbrick, 2009 [40] & Op + GKRS & 15 & 20 & 20 & 60 \\
\hline Jagannathan, 2009 [41] & Op + GKRS & 47 & 11 & 6.4 & 72.3 \\
\hline Robbins, 2012 [42] & Op + SRS & 85 & 12.1 & 18.8 & 55.3 \\
\hline Johnson, 2016 [43] & Op + GKRS & 112 & 12.9 & 15.6 & NA \\
\hline Brown, 2017 [9] & $O p+S R S$ & 98 & 12.2 & $19.6(6 \mathrm{~m})$ & NA \\
\hline Mahajan, 2017 [21] & $O p+S R S$ & 63 & 17 & 28 & 58 \\
\hline
\end{tabular}


"pseudoprogression" on imaging and patients and tumor mark-up differences between trials. [9] Although there has been some discrepancy in the literature regarding to local control rates in patients receiving post-operative SRS (Table 2), these studies nevertheless support the combination use of surgery and SRS as an effective way to treat brain oligometastasis to delay WBRT and the associated neurocognitive and quality of life decline.

The drawbacks for post-operative SRS include the need for cavity margin expansion, the unpredictability of patients' postoperative course and potential delay in SRS treatment after surgery. Soltys et al. analyzed 76 post-operative SRS cases and demonstrated that increasing conformality index significantly correlated with improved $\mathrm{LC}$ and concluded that a $2-\mathrm{mm}$ margin should be used around the resection cavity due to the possible imprecise nature of defining the target volume in a post-surgical setting. [22] Therefore, clinicians began to investigate an alternative paradigm of using preoperative SRS to reach excellent local control and preserve cognitive function.

Atalar et al. retrospectively analyzed the risk of leptomeningeal disease (LMD) in 175 patients with BMs treated with post-operative SRS and found that 13\% developed LMD 5 months following SRS. [23] In Mahajan's study, the LMD reached $28 \%$ at 12 month in post-operative SRS arm as compared to $16 \%$ in observation arm, though the difference did not reach statistical significance. It was, therefore, hypothesized that pre-resection SRS would improve the risk of LMD by sterilizing microscopic, dislodged tumor cells to prevent spread during surgery. $[23,24]$ In addition, another potential advantage of pre-operative SRS is a theoretical increased response to radiation due to intact vasculature and greater peri-tumoral oxygen content. [25-27] Studies have shown that lower doses of radiation are required for tumor control when the tumor has an intact blood supply and is oxygenated. This is due to radiation-induced DNA damage that ionizes oxygen molecules and generates oxygen -based free radicals which in turn damage nearby DNA resulting in tumor killing. $[25,26]$ In the setting of BMs, it is plausible that lower radiation doses are needed to control microscopic disease if the SRS is given prior to surgery. [26]

The first pre-operative SRS study was published by Asher et al where 47 patients were treated consecutively with neoadjuvant SRS before surgical resection, with 24 of those patients analyzed as part of a prospective trial, and the results showed 6-month and 12-month LC rate of 97.8 and $85.6 \%$ respectively (Table 3). [28] Subsequently Patel et al performed a multi-institutional retrospective comparison of outcomes and toxicities for pre-operative SRS compared to post-operative SRS for 180 patients. [29] The planning target volume (PTV) of pre-operative SRS had $0 \mathrm{~mm}$ margin expansion from gross tumor volume (GTV) compared to $2 \mathrm{~mm}$ margin for PTV of post-operative SRS. The study did not note any statistical difference in the rates of local recurrence, distant brain recurrence, and OS but the pre-operative SRS cohort demonstrated significantly lower rates of symptomatic $\mathrm{RN}(4.9 \%$ vs. $16.4 \%, p=0.01)$ and LMD $(3.2 \%$ vs. $16.6 \%, \mathrm{p}=0.01)$ than their post-operative SRS counterpart. [29] The abstract of an updated retrospective analysis of 117 patients with 125 lesions treated with pre-op SRS is now available online (https://www.redjournal.org/article/S0360-3016(18)31346-4/fulltext) and reported the 1 and 2-year cavity LC rate to be 80.1 and $74.9 \%$, distant in-brain failure (DBF): 45.3 and $60.2 \%$, and LMD: 4.3 and $4.3 \%$, respectively. Nevertheless, the results were likely limited by some intrinsic selection bias, as the two retrospective cohort groups were statistically different in their baseline performance status (Figure 1).

In this prospective phase II trial, we will establish the efficacy of pre-operative SRS in local disease control. Since the tumor will be resected within 4 days of the delivery of the radiation, we will treat lesions up to $5 \mathrm{~cm}$ in size with SRS. In addition, there is no available published literature that describes early tumor cell molecular responses to radiosurgical doses of ionizing radiation in

Table 3 Published studies of Pre-op SRS prior to Metastases Resection

\begin{tabular}{|c|c|c|c|c|c|c|c|}
\hline \multirow[t]{2}{*}{ Study } & \multirow{2}{*}{$\begin{array}{l}\text { Treatment } \\
\text { Modalities } \\
\text { (Number of } \\
\text { patients) }\end{array}$} & \multirow[t]{2}{*}{ Target } & \multirow{2}{*}{$\begin{array}{l}\text { Median } \\
\text { survival } \\
\text { (months) }\end{array}$} & \multicolumn{4}{|l|}{ Outcomes } \\
\hline & & & & LR (\%) & DBF (\%) & LMD (\%) & $\begin{array}{l}\text { Symptomatic } \\
\text { RN (\%) }\end{array}$ \\
\hline Asher, 2014 [28] & PreOP SRS (47) & $\mathrm{GTV}=\mathrm{PTV}$ & NA & 14.4 (1 yr) & $38.2(1 \mathrm{yr})$ & NA & NA \\
\hline Patel, 2016 [29] & $\begin{array}{l}\text { PreOP SRS (66) } \\
\text { Vs. } \\
\text { Postop SRS (114) }\end{array}$ & $\begin{array}{l}\text { GTV }=\text { PTV } \\
\text { PTV }=\text { cavity }+ \\
1-2 \text { mm margin }\end{array}$ & $\begin{array}{l}17.1 \\
13.5\end{array}$ & $\begin{array}{l}15.9(1 \mathrm{yr}) \\
12.6(1 \mathrm{yr})\end{array}$ & $\begin{array}{l}32(1 \mathrm{yr}) \\
39.1(1 \mathrm{yr})\end{array}$ & $\begin{array}{l}3.2(1 \mathrm{yr}) \\
3.2(2 \mathrm{yr}) \\
8.3(1 \mathrm{yr}) \\
16.6(2 \mathrm{yr})\end{array}$ & $\begin{array}{l}4.9(2 \mathrm{yr}) \\
16.4(2 \mathrm{yr})\end{array}$ \\
\hline Patel, 2017 [44] & $\begin{array}{l}\text { PreOP SRS (66) } \\
\text { Vs. } \\
\text { Postop WBRT [36] }\end{array}$ & $\begin{array}{l}\text { GTV }=\text { PTV } \\
\text { PTV }=\text { cavity }+ \\
1-2 \text { mm margin }\end{array}$ & $\begin{array}{l}13.9 \\
12.6\end{array}$ & $\begin{array}{l}24.5(2 \mathrm{yr}) \\
25.1(2 \mathrm{yr})\end{array}$ & $\begin{array}{l}53.2(2 \mathrm{yr}) \\
45(2 \mathrm{yr})\end{array}$ & $\begin{array}{l}3.5(2 \mathrm{yr}) \\
9(2 \mathrm{yr})\end{array}$ & $\begin{array}{l}5.6(2 \mathrm{yr}) \\
0(2 \mathrm{yr})\end{array}$ \\
\hline $\begin{array}{l}\text { Prabhu, } 2018 \\
\text { (Abstract only) }\end{array}$ & Pre-OP SRS (117) & $\mathrm{GTV}=\mathrm{PTV}$ & 17.2 & $\begin{array}{l}19.9(1 \mathrm{yr}) \\
25.1(2 \mathrm{yr})\end{array}$ & $\begin{array}{l}45.3(1 \mathrm{yr}) \\
60.2(2 \mathrm{yr})\end{array}$ & $\begin{array}{l}4.3(1 \mathrm{yr}) \\
4.3(2 \mathrm{yr})\end{array}$ & $\begin{array}{l}2.6(1 \mathrm{yr}) \\
4.8(2 \mathrm{yr})\end{array}$ \\
\hline
\end{tabular}


humans. We will simultaneously perform an exploratory analysis regarding histologic and molecular changes after radiosurgery for specimens removed to determine correlation between response to radiation at tumor margin and LC. This analysis will potentially provide molecular prognostic data for local and overall outcomes of patients with BMs.

\section{Study goals and objectives Primary objective}

To evaluate 6-month in-brain local control utilizing pre-operative SRS followed by surgical resection for up to 4 brain metastases.

\section{Secondary objectives}

- Overall survival

- Progression free survival

- Distant-in-brain failure

- Rate of leptomeningeal spread

- Rate of radiation necrosis.

\section{Exploratory objectives}

Molecular studies to investigate the relationship between radiation dose and DNA damage in tumor tissue. In addition, characterization of early histologic and molecular changes, in terms of gene expression, seen within the tumor following radiation.

\section{Methods/design}

\section{Study design}

This is a single-center, single-cohort, single-arm, prospective phase II trial to determine the local control at 6 months utilizing pre-operative SRS followed by surgery within 1-4 days of radiation treatment in neurologically symptomatic patients with up to 4 brain metastases.

\section{Study population}

Patients with 1-4 metastatic lesions in the brain identified on a diagnostic brain MRI or CT with at least one meeting the criteria for surgical resection i.e. symptomatic or size $>3 \mathrm{~cm}$, will be identified as potential study candidates. Amongst the study candidates, patients meeting the inclusion and exclusion criteria (Table 4) will be eligible to enroll in the study. Eligible patients who complete the Informed Consent Process will be registered in the OnCore database and assigned a patient ID number for the clinical study.

\section{Trial status and project duration}

The trial is scheduled to recruit 44 patients and is currently recruiting. The projected duration for the study is 3 years. The time line is outlined in Table 6 .
Table 4 Inclusion and Exclusion Criteria

Inclusion Criteria

1. Radiographically confirmed solid tumor brain metastases

2. Criteria for surgical resection of at least one metastasis per neurosurgeon discretion

3. A diagnostic MRI Brain or CT Head demonstrating the presence of 1-4 solid tumor brain metastases and lesion to be resected no more than $5 \mathrm{~cm}$ in any direction, performed within 30 days prior to stereotactic radiosurgery. If multiple lesions are present, then the total brain metastases volume can be no more than $30 \mathrm{~cm}^{3}$ excluding the lesion to be resected.

4. For known primary, ds-GPA estimated median survival no less than 6 months

5. For unknown primary, GPA estimated median survival no less than 6 months

6. Surgical candidate per neurosurgeon discretion

7. Surgical resection able to be performed within 1-4 days after radiosurgery

8. Stereotactic radiosurgery candidate per radiation oncologist

9. $\geq 18$ years old at the time of informed consent

10. Ability to provide written informed consent and HIPAA authorization

11. Platelet count $>100 \mathrm{k} / \mathrm{ml}, \mathrm{Hgb}>7.5 \mathrm{~g} / \mathrm{dL}, \mathrm{INR}<1.3$, ANC $>1.5 \mathrm{k} / \mathrm{ml}$

12. Patients currently on cytotoxic chemotherapy or immunotherapy are eligible, not including anti-VEGF therapy

Exclusion Criteria

1. Patients who received anti-VEGF therapy within 6 weeks prior to enrollment

2. Major medical illnesses or psychiatric impairments, which in the investigator's opinion will prevent administration or completion of the protocol therapy and/or interfere with follow-up

3. Patients with more than 4 brain metastases on MRI Brain or CT Head

4. Lesion to be resected is more than $5 \mathrm{~cm}$

5. Total volume of metastatic disease more than $30 \mathrm{~cm} 3$ excluding lesion to be resected

6. Patients with leptomeningeal metastases documented by MRI or CSF evaluation

7. Previous whole brain radiation therapy

8. Previous radiation therapy to lesion to be resected

9. Planned adjuvant focal therapy including additional radiation therapy to the brain

10. Not a surgical candidate per neurosurgeon's discretion

11. Not a radiosurgical candidate per radiation oncologist's discretion

12. Surgery unable to be performed between 1 and 3 days after radiosurgery

13. Women who are pregnant or nursing are not eligible as treatment involves unforeseeable risks to the fetus or child

14. Patients who have a known primary and have an estimated median survival less than 6 months per ds-GPA

15. Patients who have an unknown primary and have an estimated median survival less than 6 months per GPA

\section{Stereotactic radiosurgery}

SRS will be delivered utilizing gamma knife or linear accelerator-based techniques. With the Leksell Gamma Knife Perfexion', Leksell GammaPlan ${ }^{\circ}$ will be used to generate the treatment plan with respect to the head frame coordinate system created by localization. Target volume and isocenter determination will be based on a brain MRI with the patient's head in the stereotactic frame. Linear accelerator based stereotactic localization will be performed using the Encompass ${ }^{\oplus}$ SRS thermoplastic mask 
immobilization system. The patient will undergo a $1 \mathrm{~mm}$ slice thickness helical CT scan that will be fused with the MRI brain T1-weighted post-contrast axial scan used for target delineation. The CT-MRI fusion maximum correlation error must be less than $1.5 \mathrm{~mm}$.

The prescribed dose will be based on tumor diameter per RTOG 90-05 dosing criteria with the exception that the largest lesion diameter to be treated with 15 Gy will be $5 \mathrm{~cm}$ (Table 5). [27] Since it has been shown that brain metastases up to $4.5 \mathrm{~cm}$ can be safely treated with 15 Gy SRS either alone or with WBRT with no reported toxicity at $2-3$ months following treatment. [30]

SRS will be delivered to each lesion that has not previously undergone treatment. Due to the volumetric summation constraint for the remaining metastases, no single, non-resected lesion greater than $4 \mathrm{~cm}$ will be allowed in the study. If any two lesions are within 0.8 to $2 \mathrm{~cm}$ of each other, the intervening midplane dose will not exceed $13 \mathrm{~Gy}$. This may require treating each respective target with a lesser dose than dictated by the above dosing criteria to minimize toxicity. The dose to the critical structures, including optic pathway, brainstem, cochlea and medulla, must meet constraints as designated by Task Group 101. [31] If the above constraints cannot be met utilizing the prescribed radiosurgery dose, then the highest dose to the target volume will be used such that constraints can be met. This will be considered a minor deviation.

\section{Surgical resection}

At least one of the 4 lesions has to be either larger than $3 \mathrm{~cm}$ or symptomatic to meet the surgical resection criteria. One to four days after radiosurgery, the dominant lesion(s) will be maximally resected and labeled tissue will be sent to the neuropathology department for clinical diagnosis and radiobiological correlative studies. If for safety concern or other considerations, gross total resection is not reached, the residual disease in the setting of subtotal resection will be closely observed given that it has been treated with a definitive dose of SRS, reserving salvage local therapy for cases of progression. [29] Patients who received subtotal resection will be recorded and analyzed as well for risk stratification.

Table 5 Radiosurgery dose criteria

\begin{tabular}{ll}
\hline Maximum Tumor Diameter & Prescribed Dose \\
\hline$\leq 20 \mathrm{~mm}$ & $24 \mathrm{~Gy}$ \\
$21-30 \mathrm{~mm}$ & $18 \mathrm{~Gy}$ \\
$31-40 \mathrm{~mm}$ & $15 \mathrm{~Gy}$ \\
$40-50 \mathrm{~mm}$ & $15 \mathrm{~Gy}$ \\
\hline
\end{tabular}

\section{Correlative analysis}

For the radiobiological studies, tissues will be examined for a) pathologic diagnosis b) immunohistochemistry for immune cell infiltrates and c) mitochondrial histochemistry to address DNA damage. In addition, to understand the effect of radiation dosing on tumor tissue at the molecular level, RNA and DNA sequencing will be performed on peripheral and central sites from the tumor specimen of each patient's tumor samples. The early cellular gene expression changes in response to high dose radiation will be assessed. DNA sequencing and RNA expression will also be correlated with all clinical outcomes to establish prognostic molecular classifications. Protein analysis for apoptotic pathway activation will also be done on tumor cells to assess radiation induced tumor cell killing.

\section{Response and progression assessment in neuro-oncology brain metastases (RANO-BM) [32]}

Following delivery of SRS and surgical resection, all patients will be assessed for their clinical performance status (GPA/ds-GPA/ ECOG performance status/KPS) as well as toxicity at follow-up intervals as detailed in Table 6. Serial MRIs will be analyzed per RANO-BM criteria for assessment of LC, DBF and cranial progression free survival. [32] Initiation or continuation of chemotherapy, immunotherapy or other systemic agents is allowed per medical oncologist discretion.

\section{Leptomeningeal disease and radiation necrosis}

Assessment for LMD and RN will be performed using contrast-enhanced MRI scans. LMD is defined as new subarachnoid, ventricular or parenchymal enhancing nodules, focal or diffuse pial enhancement, ependymal, sulcal, folia or cranial nerve enhancement. [33] $\mathrm{RN}$ is defined as a contrast-enhancing lesion with surrounding edema within previous radiation treatment fields. MR spectroscopy and perfusion weighted imaging (PWI) sequences will be analyzed to differentiate between RN and recurrent tumor. [34, 35]

\section{General monitoring}

For patients presenting with signs and symptoms relatable to peri-tumoral edema, dexamethasone will be prescribed at a dose level per clinician judgment. For patients presenting with seizure, anti-seizure medication will be prescribed at a dose level per clinician judgment. No specific type of anti-seizure medication is recommended or prohibited. Subjects will be encouraged to $r$ emain in the study and maintain regular follow-up. Possible reasons for early withdrawal may include, but are not limited to, the following: 
Table 6 Study Protocol and follow up timeline

\begin{tabular}{|c|c|c|c|c|c|c|}
\hline & $\begin{array}{l}\text { Screening (within } \\
30 \text { days of SRS) }\end{array}$ & $\begin{array}{l}\text { Stereotactic } \\
\text { radiosurgery }\end{array}$ & $\begin{array}{l}\text { Surgery (1-4 } \\
\text { days post SRS) }\end{array}$ & $\begin{array}{l}1 \text { Month Follow Up } \\
\text { (30 days post SRS) }\end{array}$ & $\begin{array}{l}\text { Follow Up (every } \\
3 \text { m until } 2 \text { yrs) }\end{array}$ & $\begin{array}{l}\text { Long Term Follow } \\
U^{c}(>2 \text { yr. post SRS) }\end{array}$ \\
\hline Radiation oncology consult & $x$ & & & & & \\
\hline Neurosurgical consult & $x$ & & & & & \\
\hline Medical History & $x$ & & & $x$ & $x$ & $x$ \\
\hline Physical Examination & $x$ & & & $x$ & $x$ & $x$ \\
\hline Vitals & $x$ & $x$ & $x$ & $x$ & $x$ & $x$ \\
\hline $\begin{array}{l}\text { ds-GPA/GPA/ECOG } \\
\text { performance status/KPS }\end{array}$ & $x$ & & & $x$ & $x$ & $x$ \\
\hline $\begin{array}{l}\text { Diagnostic MRI Brain or } \\
C T \text { Head }\end{array}$ & $x$ & & & & & \\
\hline MRI Brain Planning Scan ${ }^{f}$ & & $x$ & & & & \\
\hline $\begin{array}{l}\text { WBC, Hgb, platelets, } \\
\text { INR, ANC }\end{array}$ & $x$ & & $x$ & & & \\
\hline Urine pregnancy test & $x$ & & & & & \\
\hline Toxicity assessment & & & & $x$ & $x$ & \\
\hline MRI Brain ${ }^{e}$ & & & & & $x$ & $x$ \\
\hline Tissue collection & & & $x$ & & & \\
\hline
\end{tabular}

${ }^{a}$ Variations of $+/-14$ days from the scheduled visit are permitted

bVariations of +/- 30 days from the scheduled visit are permitted

'Subjects will be followed at physician's discretion, approximately every 6 months after 2 years post SRS, per standard of care. Any MRI Brain, physical exam or vitals obtained at these appointments will gathered. However, if these procedures are not performed per standard of care, this will not be a deviation ${ }^{\mathrm{d}}$ Repeating $\mathrm{Hgb}$, platelets, INR and ANC at time of surgery is per discretion of neurosurgeon

e MRI Brain performed at Indiana University will have sequences including contrast, no contrast, FLAIR, DTI and PWI. If patient receives MRI Brain outside of Indiana University, a minimum of contrast, no contrast and FLAIR will need to be obtained and all sequences mentioned above are encouraged

fVariations of -30 days from the scheduled visit are permitted for linear accelerator based SRS, and may include the baseline screening MRI at the treating radiation oncologist's discretion

- Subject decides to withdraw from the study. This decision must be an "independent decision" that is documented in the source documentation

- The Principal Investigator and/or treating physician may choose to withdraw a subject from the study if there are safety or other concerns.

- Subject becomes pregnant.

- Subject non-compliance.

- Subject lost to follow-up.

- Subject death.

\section{Follow-up}

Time-to-event analyses will be measured from the date of completion of radiation therapy (Day 0). As outlined in Table 6 patients will be followed at 1-month post radiosurgery, then at 3 month and every 3 months thereafter for 2 years. A detailed medical history, toxicity assessment and physical examination including vital signs will be performed at each visit. Each follow-up starting from 3 month follow up will also include a MRI with the following sequences: without contrast, with contrast, FLAIR, DTI and PWI. The MRI will be analyzed per RANO-BM criteria [32] for assessment of local control, distant in-brain failure and cranial progression free survival. The MRI will also be analyzed for radiation necrosis and leptomeningeal disease as discussed in methodology section. Cases concerning for radiation necrosis will be further analyzed using MR spectroscopy. After the 2 year follow up period, subjects will be followed according to their treating physician per standard of care approximately every 6 months). Patients will continue to be followed for survival information until death. All AEs considered related to trial medication will be followed until resolution, return to baseline, or deemed clinically insignificant, even if this occurs post-trial.

\section{Safety considerations}

Investigators will conduct continuous review of data and patient safety. Monthly review meetings for moderate risk trials are required and will include the principal investigator, clinical research specialist and/or research nurse. Adverse events (AEs) will be recorded from the time of study intervention and for at least 30 days after treatment discontinuation, regardless of whether or not the event(s) are considered related to trial medications. Any death occurring within 30 days after the study intervention will be reported as a serious adverse event (SAE) regardless of attribution. AEs will be reported to the IRB within 5 days from becoming aware of the event if they are: [1] unexpected, [2] related or possibly related to study participation, and [3] suggests that the research places subject(s) or others at greater risk of harm than was previously known. SAE reports are entered into OnCore ${ }^{\circ}$ monthly and reviewed by 
the Data Safety Monitoring Committee (DSMC) chair and/ or coordinator monthly. Findings will be reported to the full DSMC at the time of study review. At any time during the trial, the study will be closed early if it is the opinion of the investigators that the risks (or benefits) to the patient warrant early closure of the study. Alternatively, the DSMC may initiate suspension or early closure of the study based on its review of the investigator reports.

\section{Data management}

This study will utilize electronic Case Report Form completion in the OnCore ${ }^{\circ}$ database. A calendar of events and required forms are available in OnCore ${ }^{\circ}$. The OnCore $^{\odot}$ database is a comprehensive, web-based, Clinical Trial Management System (CTMS) which utilizes an Oracle database. All documents will be kept according to applicable federal guidelines. Clinical trial data in OnCore ${ }^{\odot}$ are periodically monitored by the IU Simon Cancer Center Data Safety Monitoring Committee.

\section{Quality assurance}

Records of IRB review and approval of all documents pertaining to this study will be kept on file in the Clinical Trials Office and are subject to inspection at any time during the study. Periodic status reports will be submitted to the Institutional Review Board at least yearly, as well as notification of completion of the study and a final report within 3 months of study completion or termination. Accrual data will be entered into the IU Simon Cancer Center OnCore ${ }^{\bullet}$ system. The Protocol Progress Committee (PPC) reviews study accrual twice per year while the PPC coordinator reviews accrual quarterly.

\section{Project Management}

Patient recruitment is based on the referral from neurosurgeons, medical oncologists, radiation oncologist, primary care physicians, or self-referral. The principal investigators are responsible for checking eligibility and explaining the study principles, including detailed experimental schedule, investigational treatment, potential risks, and benefits. Radiation oncologists, neurosurgeons, and medical oncologists will be responsible for the consults, clinical treatments and follow up evaluations for the respective specialties. Pathologists will be performing histochemistry, immunochemistry and assist on other aspect of correlative studies. Statistical analysis will be performed by statisticians from the Department of Biostatistics at Indiana University School of Medicine.

\section{Statistical analysis}

A sample size of 44 patients will provide $82 \%$ power with an alpha $=0.05$ to determine if the proportion of patients with local control at 6 months is $<=83 \%$ or $>=95 \%$. For the primary objective of 6-month local control for pre-operative SRS followed by surgical resection of the brain metastases, the proportion of patients who have local control at 6 months will be calculated along with a 95\% confidence interval. Testing the observed proportion against a baseline 6-month local control proportion of $83 \%$ at a one-sided alpha of 5\% using a binomial test will be done. The proportion of patients who have in-brain distant failure, radiation necrosis, and leptomeningeal spread in the evaluated patients will be summarized and exact binomial 95\% confidence intervals will be determined. Additionally, time to local failure, distant in-brain progression, and overall survival will be calculated and analyzed using Kaplan-Meier methods with the medians estimated with a $95 \%$ confidence interval. The probability rates will be provided for 6 months, 1 year, and 2 years. Finally, the tissue biomarkers of interest in the molecular study will be correlated with treated lesion location, in-brain local control, in-brain distant control, and overall survival using Cox proportional hazards regression. Time dependent ROC curves will be generated to assess predictive ability.

\section{Discussion}

To date, most studies have evaluated the role of SRS post-operatively in patients with clear indications for surgical management of BMs. [13, 20] We believe that pre-operative SRS merits further investigation as this technique has several clinical and radiobiological advantages, including precise tumor definition, possible sterilization of the tumor margin prior to surgical resection leading to decreased microscopic spread of disease during surgery, removal of irradiated tissue, and a theoretical radiobiological advantage of intact vasculature optimizing oxygenation. Additionally, all prior SRS studies limit indication of SRS to lesion $<4 \mathrm{~cm}$ in size due to dose related toxicity. Since we will be resecting the lesion post SRS, we will include lesions up to $5 \mathrm{~cm}$ in size.

We expect that, compared with historic LC rate associated with post-operative SRS, pre-operative SRS will have a higher LC rate as well as decreased risk of LMD and symptomatic RN. In terms of radiobiological studies, we expect differential gene expression profile in the tissue from the center of the lesion, which receives $50 \%$ greater radiation dose compared to the periphery of the lesion. In addition, we expect to see higher percentage of immune cell infiltrate in the radiation treated lesions.

Our exploratory analysis regarding histologic and molecular changes after radiosurgery will determine if any correlation between immune response to radiation at tumor margin and local control exists. This may characterize a group of patients requiring additional therapy after pre-operative radiosurgery and surgical resection for maximal tumor control. 


\section{Abbreviations}

BM: Brain metastasis; DBF: Distant-in-brain failure; ECOG: Eastern Cooperative Oncology Group; GPA/ds-GPA: Graded prognostic assessment/Diagnosis-specific graded prognostic assessment; GTV: Gross target volume; KPS: Karnofsky Performance Status; LC: Local control; LMD: Leptomeningeal disease; LR: Local recurrence; OS: Overall survival; PTV: Planning target volume; RN: Radiation necrosis; SRS: Stereotactic radiosurgery; WBRT: Whole brain radiation therapy

\section{Acknowledgements}

Authors would like to thank Heather Cero, Jennifer Pencek, and Lauren Snyder for research administrative support.

\section{Funding}

This study is supported by IU Health Values Fund (Indiana University Health Grant number VFR-456-Dey) financed by Indiana CTSI (Clinical and Translational Science Institute), Indianapolis IN, USA.

\section{Availability of data and materials}

The dataset used and/or analyzed during the current study will be published in the form of manuscripts upon completion of the study and will be available from the corresponding author after publication on reasonable request.

\section{Authors' contributions}

Study conception MD, NA and GW. Initial Study design: MD, NA and GW. Revision of study design and protocol: MD, NA, GW, AV. Study coordination: MD, GW, AV. Participating centers: Indiana University Methodist Hospital, Indianapolis, IN 46202, USA. Drafting the manuscript: WH, SS, JM, CK, MS, TP, $J J$, MD. All authors read and approved the final manuscript.

\section{Ethics approval and consent to participate}

This study will be conducted in compliance with international Conference on Harmonization-Good Clinical Practice (Food and Drug Administration guideline) and with all applicable federal (including 21 CFR parts 56 \& 50), state and local laws. The Institutional Review Board (IRB) has approved the protocol and the informed consent form, for this study. Informed consent and HIPAA authorization will be obtained prior to patients' enrollment in the study and registration in the OnCore ${ }^{\oplus}$ database.

\section{Consent for publication}

Not applicable.

\section{Competing interests}

The authors declare that they have no competing interests.

\section{Publisher's Note}

Springer Nature remains neutral with regard to jurisdictional claims in published maps and institutional affiliations.

\section{Author details}

'Department of Neurosurgery, Indiana University School of Medicine, Indiana University Purdue University Indianapolis, Neuroscience Research Building, 320 W 15th Street, NB 400A, Indiana, IN 46202, USA. ${ }^{2}$ Department of Radiation Oncology, Indiana University School of Medicine, Indiana University Purdue University Indianapolis, Indiana, USA. ${ }^{3}$ Department of Pathology, Indiana University School of Medicine, Indiana University Purdue University Indianapolis, Indiana, USA.

Received: 3 October 2018 Accepted: 9 November 2018 Published online: 20 December 2018

\section{References}

1. Franchino F, Ruda R, Soffietti R. Mechanisms and therapy for Cancer metastasis to the brain. Front Oncol. 2018:8:161.

2. Steeg PS, Camphausen KA, Smith QR. Brain metastases as preventive and therapeutic targets. Nat Rev Cancer. 2011;11(5):352-63.

3. Patchell RA, Tibbs PA, Walsh JW, Dempsey RJ, Maruyama Y, Kryscio RJ, et al. A randomized trial of surgery in the treatment of single metastases to the brain. N Engl J Med. 1990;322(8):494-500.
4. Vecht CJ, Haaxma-Reiche H, Noordijk EM, Padberg GW, Voormolen JH, Hoekstra FH, et al. Treatment of single brain metastasis: radiotherapy alone or combined with neurosurgery? Ann Neurol. 1993;33(6):583-90.

5. Tabouret E, Chinot O, Metellus P, Tallet A, Viens P, Goncalves A. Recent trends in epidemiology of brain metastases: an overview. Anticancer Res. 2012;32(11):4655-62

6. Chang EL, Wefel JS, Hess KR, Allen PK, Lang FF, Kornguth DG, et al. Neurocognition in patients with brain metastases treated with radiosurgery or radiosurgery plus whole-brain irradiation: a randomised controlled trial. Lancet Oncol. 2009;10(11):1037-44.

7. Warrington JP, Ashpole N, Csiszar A, Lee YW, Ungvari Z, Sonntag WE. Whole brain radiation-induced vascular cognitive impairment: mechanisms and implications. J Vasc Res. 2013;50(6):445-57.

8. Khuntia D, Brown P, Li J, Mehta MP. Whole-brain radiotherapy in the management of brain metastasis. J Clin Oncol. 2006;24(8):1295-304

9. Brown PD, Ballman KV, Cerhan JH, Anderson SK, Carrero XW, Whitton AC, et al. Postoperative stereotactic radiosurgery compared with whole brain radiotherapy for resected metastatic brain disease (NCCTG N107C/CEC.3): a multicentre, randomised, controlled, phase 3 trial. Lancet Oncol. 2017;18(8):1049-60.

10. Brown PD, Jaeckle K, Ballman KV, Farace E, Cerhan JH, Anderson SK, et al. Effect of radiosurgery alone vs radiosurgery with whole brain radiation therapy on cognitive function in patients with 1 to 3 brain metastases: a randomized clinical trial. JAMA. 2016;316(4):401-9.

11. Kondziolka D, Shin SM, Brunswick A, Kim I, Silverman JS. The biology of radiosurgery and its clinical applications for brain tumors. Neuro-Oncology. 2015;17(1):29-44.

12. Flores BC, Patel AR, Timmerman RD, Barnett SL. From Patchell to Brown: an evidence-based evolution of the role of radiotherapy on the Management of Brain Metastases. World Neurosurg. 2016;85:10-4.

13. Prabhu RS, Patel KR, Press RH, Soltys SG, Brown PD, Mehta MP, et al. Preoperative Vs Postoperative Radiosurgery For Resected Brain Metastases: A Review. Neurosurgery. 2018. [Epub ahead of print].

14. Badiyan SN, Regine WF, Mehta M. Stereotactic radiosurgery for treatment of brain metastases. J Oncol Pract. 2016;12(8):703-12.

15. Higuchi Y, Yamamoto M, Serizawa T, Aiyama H, Sato Y, Barfod BE. Modern management for brain metastasis patients using stereotactic radiosurgery: literature review and the authors' gamma knife treatment experiences. Cancer Manag Res. 2018;10:1889-99.

16. Serizawa T, Higuchi Y, Yamamoto M, Matsunaga S, Nagano O, Sato Y, et al. Comparison of treatment results between 3- and 2-stage gamma knife radiosurgery for large brain metastases: a retrospective multi-institutional study. J Neurosurg. 2018:1-11. [Epub ahead of print].

17. Fuentes R, Osorio D, Exposito Hernandez J, Simancas-Racines D, Martinez-Zapata MJ, Bonfill CX. Surgery versus stereotactic radiotherapy for people with single or solitary brain metastasis. Cochrane Database Syst Rev. 2018;8:CD012086.

18. Patchell RA. The management of brain metastases. Cancer Treat Rev. 2003;29(6):533-40.

19. Mut M. Surgical treatment of brain metastasis: a review. Clin Neurol Neurosurg. 2012;114(1):1-8.

20. Gans JH, Raper DM, Shah AH, Bregy A, Heros D, Lally BE, et al. The role of radiosurgery to the tumor bed after resection of brain metastases. Neurosurgery. 2013;72(3):317-25 discussion 25-6.

21. Mahajan A, Ahmed S, McAleer MF, Weinberg JS, Li J, Brown P, et al. Postoperative stereotactic radiosurgery versus observation for completely resected brain metastases: a single-Centre, randomised, controlled, phase 3 trial. Lancet Oncol. 2017;18(8):1040-8.

22. Soltys SG, Adler JR, Lipani JD, Jackson PS, Choi CY, Puataweepong P, et al. Stereotactic radiosurgery of the postoperative resection cavity for brain metastases. Int J Radiat Oncol Biol Phys. 2008;70(1):187-93.

23. Taillibert S, Laigle-Donadey F, Chodkiewicz C, Sanson M, Hoang-Xuan K, Delattre JY. Leptomeningeal metastases from solid malignancy: a review. J Neuro-Oncol. 2005;75(1):85-99.

24. Atalar B, Modlin LA, Choi CY, Adler JR, Gibbs IC, Chang SD, et al. Risk of leptomeningeal disease in patients treated with stereotactic radiosurgery targeting the postoperative resection cavity for brain metastases. Int J Radiat Oncol Biol Phys. 2013;87(4):713-8.

25. Ward JF. The complexity of DNA damage: relevance to biological consequences. Int J Radiat Biol. 1994;66(5):427-32.

26. Hall EJGA. Radiobiology for the radiologist: Lippincott Williams \& Wilkins; 2011.

27. Shaw E, Scott C, Souhami L, Dinapoli R, Kline R, Loeffler J, et al. Single dose radiosurgical treatment of recurrent previously irradiated primary brain 
tumors and brain metastases: final report of RTOG protocol 90-05. Int J Radiat Oncol Biol Phys. 2000;47(2):291-8.

28. Asher AL, Burri SH, Wiggins WF, Kelly RP, Boltes MO, Mehrlich M, et al. A new treatment paradigm: neoadjuvant radiosurgery before surgical resection of brain metastases with analysis of local tumor recurrence. Int J Radiat Oncol Biol Phys. 2014;88(4):899-906.

29. Patel KR, Burri SH, Asher AL, Crocker IR, Fraser RW, Zhang C, et al. Comparing preoperative with postoperative stereotactic radiosurgery for Resectable brain metastases: a multi-institutional analysis. Neurosurgery. 2016;79(2):279-85.

30. Li B, Yu J, Suntharalingam M, Kennedy AS, Amin PP, Chen Z, et al. Comparison of three treatment options for single brain metastasis from lung cancer. Int J Cancer. 2000;90(1):37-45.

31. Benedict SH, Yenice KM, Followill D, Galvin JM, Hinson W, Kavanagh B, et al. Stereotactic body radiation therapy: the report of AAPM task group 101. Med Phys. 2010;37(8):4078-101.

32. Lin NU, Lee EQ, Aoyama H, Barani IJ, Barboriak DP, Baumert BG, et al. Response assessment criteria for brain metastases: proposal from the RANO group. Lancet Oncol. 2015;16(6):e270-8.

33. Le Rhun E, Taillibert $\mathrm{S}$, Chamberlain MC. Carcinomatous meningitis: leptomeningeal metastases in solid tumors. Surg Neurol Int. 2013; 4(Suppl 4):S265-88.

34. Shah R, Vattoth S, Jacob R, Manzil FF, O'Malley JP, Borghei P, et al. Radiation necrosis in the brain: imaging features and differentiation from tumor recurrence. Radiographics. 2012;32(5):1343-59.

35. Barajas RF, Chang JS, Sneed PK, Segal MR, McDermott MW, Cha S. Distinguishing recurrent intra-axial metastatic tumor from radiation necrosis following gamma knife radiosurgery using dynamic susceptibility-weighted contrast-enhanced perfusion MR imaging. AJNR Am J Neuroradiol. 2009;30(2):367-72.

36. Bahl G, White G, Alksne J, Vemuri L, Spear MA. Focal radiation therapy of brain metastases after complete surgical resection. Med Oncol. 2006;23(3):317-24.

37. Kim PK, Ellis TL, Stieber WW, McMullen KP, Shaw EG, McCoy TP, et al. Gamma knife surgery targeting the resection cavity of brain metastasis that has progressed after whole-brain radiotherapy. J Neurosurg. 2006;105(Suppl):75-8.

38. Iwai Y, Yamanaka K, Yasui T. Boost radiosurgery for treatment of brain metastases after surgical resections. Surg Neurol. 2008;69(2):181-6 discussion 6.

39. Mathieu D, Kondziolka D, Flickinger JC, Fortin D, Kenny B, Michaud K, et al. Tumor bed radiosurgery after resection of cerebral metastases. Neurosurgery. 2008;62(4):817-23 discussion 23-4.

40. Limbrick DD Jr, Lusis EA, Chicoine MR, Rich KM, Dacey RG, Dowling JL, et al. Combined surgical resection and stereotactic radiosurgery for treatment of cerebral metastases. Surg Neurol. 2009;71(3):280-8 disucssion 8-9.

41. Jagannathan J, Yen CP, Ray DK, Schlesinger D, Oskouian RJ, Pouratian N, et al. Gamma knife radiosurgery to the surgical cavity following resection of brain metastases. J Neurosurg. 2009;111(3):431-8.

42. Robbins JR, Ryu S, Kalkanis S, Cogan C, Rock J, Movsas B, et al. Radiosurgery to the surgical cavity as adjuvant therapy for resected brain metastasis. Neurosurgery. 2012;71(5):937-43.

43. Johnson MD, Avkshtol V, Baschnagel AM, Meyer K, Ye H, Grills IS, et al. Surgical resection of brain metastases and the risk of leptomeningeal recurrence in patients treated with stereotactic radiosurgery. Int J Radiat Oncol Biol Phys. 2016;94(3):537-43.

44. Patel KR, Burri SH, Boselli D, Symanowski JT, Asher AL, Sumrall A, et al. Comparing pre-operative stereotactic radiosurgery (SRS) to post-operative whole brain radiation therapy (WBRT) for resectable brain metastases: a multi-institutional analysis. J Neuro-Oncol. 2017;131(3):611-8.

\section{Ready to submit your research? Choose BMC and benefit from:}

- fast, convenient online submission

- thorough peer review by experienced researchers in your field

- rapid publication on acceptance

- support for research data, including large and complex data types

- gold Open Access which fosters wider collaboration and increased citations

- maximum visibility for your research: over $100 \mathrm{M}$ website views per year

At BMC, research is always in progress.

Learn more biomedcentral.com/submissions 